\title{
Fluoride has a beneficial effect on root caries
}

\author{
Abstracted from \\ Heijnsbroek M, Paraskevas S, Van der Weijden GA. \\ Fluoride interventions for root caries: a review. Oral Health Prev Dent 2007; 5: 145-152 \\ Address for correspondence: Fridus Van der Weijden, Department of Periodontology, \\ Academic Centre of Dentistry Amsterdam, Louwesweg 1, Amsterdam, The Netherlands. E-mail: ga.vd.weijden@acta.nl
}

\section{Question: Are fluoride interventions effective for the prevention of root caries in adults?}

Data Sources Medline and the Cochrane Oral Health Group trials register were searched for suitable studies.

Study selection Papers were screened independently by two authors. Randomised controlled trials (RCT), controlled trials and uncontrolled longitudinal studies of at least 3 months' duration that investigated activity and/ or incidence of root caries and were published in English were included.

Data extraction and synthesis Because of wide variation between clinical parameters evaluated for caries activity, a qualitative synthesis was presented.

Results Six studies met the inclusion criteria, five of which were RCT. Conclusions The available studies suggest that increasing the regular daily delivery of fluoride has a beneficial effect, reducing root caries.

\section{Commentary}

Root caries lesions initiate or extend onto the part of the tooth apical to the cemento-enamel junction. They occur mostly on exposed root surfaces and, in early stages, can be characterised by surface softening and discolouration without surface breakdown.

Although root caries can occur in younger individuals, it is more prevalent in older adults. With an increasing elderly dentate population, the dental profession can expect an increasing demand and need for the prevention and treatment of root caries lesions. Griffin and colleagues ${ }^{1}$ estimated that root caries incidence was $23.3 \%(95 \%$ confidence interval, 17.1-30.2\%) and suggested that older adults might have levels of new caries formation similar to, or higher than, those seen in children. Meanwhile, nursing home residents are more likely to have root caries than elderly people who live in their own homes, ${ }^{2}$ indicating the need for caries prevention programmes for older people.

This review looked at fluoride interventions for preventing caries in older people. Selecting only papers written in English does limit the number of potential studies for inclusion, but the paucity of studies conducted in this age group is still clear - particularly in the light of the robust evidence for the effectiveness of a range of fluoride interventions from Cochrane reviews. ${ }^{3-9}$ This review identifies six studies that examined fluoride toothpastes, mouthwashes and varnishes: it reaches the same conclusion as an earlier review by Leake, ${ }^{10}$ that topical fluorides are likely to be beneficial.
Root caries presents problems in the way it is described and recorded; this was an issue when attempting to combine data from the studies identified in this review. There are also undoubtedly methodological issues when working with older populations. Root caries is becoming an increasing problem for older adults, however, with the highest incidence and prevalence being seen in community-living older adults and nursing home residents, particularly those with dementia and neurological conditions. Consequently, we do need more robust evidence for future preventive programmes since there are significant health, quality of life and economic issues associated with root caries.

\section{Derek Richards}

Department of Public Health, NHS Forth Valley, Stirling, Scotland, UK

1. Griffin SO, Griffin PM, Swann JL, Zlobin N. Estimating rates of new root caries in older adults. / Dent Res 2004; 83: 634-638.

2. Kidd EA, Giedrys-Leeper E, Simons D. Take two dentists: a tale of root caries. Dent Update 2000; 27: 222-230.

3. Marinho VC, Higgins JP, Sheiham A, Logan S. Combinations of topical fluoride (toothpastes, mouthrinses, gels, varnishes) versus single topical fluoride for preventing dental caries in children and adolescents. Cochrane Database Syst Rev 2004; issue 1 .

4. Marinho VC, Higgins JP, Sheiham A, Logan S. One topical fluoride (toothpastes, or mouthrinses, or gels, or varnishes) versus another for preventing dental caries in children and adolescents. Cochrane Database Syst Rev 2004; issue 1.

5. Marinho VC, Higgins JP, Logan S, Sheiham A. Topical fluoride (toothpastes, mouthrinses, gels or varnishes) for preventing dental caries in children and adolescents. Cochrane Database Syst Rev 2003; issue 4.

6. Marinho VC, Higgins JP, Logan S, Sheiham A. Fluoride mouthrinses for preventing dental caries in children and adolescents. Cochrane Database Syst Rev 2003; issue 3.

7. Marinho VC, Higgins JP, Sheiham A, Logan S. Fluoride toothpastes for preventing dental caries in children and adolescents. Cochrane Database Syst Rev 2003; issue 1.

8. Marinho VC, Higgins JP, Logan S, Sheiham A. Fluoride varnishes for preventing dental caries in children and adolescents. Cochrane Database Syst Rev 2002; issue 3.

9. Marinho VC, Higgins JP, Logan S, Sheiham A. Fluoride gels for preventing dental caries in children and adolescents. Cochrane Database Syst Rev 2002; issue 2.

10. Leake JL. Clinical Decision Making for Caries Management in Root Surfaces. J Dent Educ. 2001; 65: 1147-1153.

Evidence-Based Dentistry (2009) 10, 12. doi:10.1038/sj.ebd.6400627 